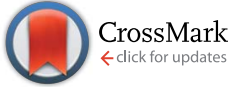

Cite this: Chem. Sci., 2016, 7, 2179

Received 6th November 2015 Accepted 4th December 2015

DOI: $10.1039 / \mathrm{c} 5 \mathrm{sc} 04232 \mathrm{a}$

www.rsc.org/chemicalscience

\title{
A case study of proton shuttling in palladium catalysis $\dagger$
}

\author{
Julien Monot, ${ }^{\text {ab }}$ Paul Brunel, ${ }^{\text {ab }}$ Christos E. Kefalidis, ${ }^{c}$ Noel Ángel Espinosa-Jalapa, ${ }^{\text {ab }}$ \\ Laurent Maron, $^{\star c}$ Blanca Martin-Vaca*ab and Didier Bourissou*ab
}

\begin{abstract}
The mechanism of alkynoic acid cycloisomerization with SCS indenediide Pd pincer complexes has been investigated experimentally and computationally. These studies confirmed the cooperation between the $\mathrm{Pd}$ center and the backbone of the pincer ligand, and revealed the involvement of a second molecule of substrate. It acts as a proton shuttle in the activation of the acid, it directs the nucleophilic attack of the carboxylic acid on the $\pi$-coordinated alkyne and it relays the protonolysis of the resulting vinyl $\mathrm{Pd}$ species. A variety of $\mathrm{H}$-bond donors have been evaluated as external additives, and polyols featuring proximal hydroxyl groups, in particular catechol derivatives, led to significant catalytic enhancement. The impact of 4-nitrocatechol and 1,2,3-benzenetriol is particularly striking on challenging substrates such as internal 4- and 5-alkynoic acids. Endo/exo selectivities up to 7.3/1 and 60-fold increase in reactivity were achieved.
\end{abstract}

\section{Introduction}

The interplay between experiment and theory is extremely powerful for the study of the mechanism of catalytic transformations, to understand the factors influencing their efficiency and selectivity, and finally to optimize their performance. ${ }^{1}$ From an experimental point of view, mechanistic proposals are typically drawn on the basis of kinetic studies, ${ }^{2}$ isotopic labeling experiments ${ }^{3}$ and characterizations of intermediates. ${ }^{4}$ On the other hand, the advent of DFT methods has revolutionized the ability of computational methods to describe chemical systems and nowadays virtually all molecular compounds, including transition metal complexes, can be investigated in extenso. Accordingly, accurate and valuable information can be gained on the entire reaction profile. Geometric and electronic structures of key intermediates and transition states can be analyzed, different mechanistic scenarios can be probed and compared, kinetic data and selectivities can be estimated. ${ }^{5}$ Combining and comparing the experimental and theoretical data is a major source of information and often helps to identify and understand the very mechanism of catalytic transformations.

aniversité de Toulouse, UPS, 118 route de Narbonne, F-31062 Toulouse, France ${ }^{b}$ CNRS, LHFA UMR5069, F-31062 Toulouse, France. E-mail: bmv@chimie.ups-tlse.fr; dbouriss@chimie.ups-tlse.fr

'Université de Toulouse, INSA, UPS, LCPNO, CNRS, UMR 5215 CNRS-UPS-INSA, 135 avenue de Rangueil, 31400 Toulouse, France. E-mail: laurent.maron@irsamc. ups-tlse.fr

$\uparrow$ Electronic supplementary information (ESI) available: Experimental details and characterization data; computational studies. See DOI: 10.1039/c5sc04232a
In light of our activities on pincer complexes, we recently reported SCS indenediide Pd complexes featuring ligand noninnocent character. ${ }^{6}$ These indenediide complexes proved very efficient in the catalytic cycloisomerization of alkynoic acids as well as $N$-tosylalkynylamides (Chart 1$).^{7}$ They do not require the presence of an external base and represent a rare example of metal-ligand cooperative catalysis involving $\mathrm{Pd} .{ }^{8}$ The catalytic system can be recycled without deactivation up to ten times and it is efficient for a large variety of substrates, giving access to 5-, 6- and even 7-membered alkylidene lactones and lactams with high selectivity (generally in favor of the exo product). The SCS indenediide Pd complexes have clearly enhanced the efficiency and extended the scope of such cycloisomerizations, but there is certainly room for further improvement. In particular, the cyclization of substrates featuring internal alkynes remains challenging. It requires much higher temperatures and longer reaction times, and the exo/endo selectivity is often modest.

Concerning the mechanism of cycloisomerization, first insights have been obtained experimentally. ${ }^{7}$ The active participation of the SCS pincer ligand to the activation of substrate has been substantiated (non-innocent character by protonation of electron-rich indenediide backbone). In

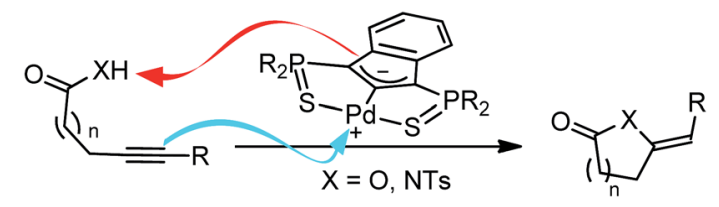

Chart 1 Cycloisomerization of alkynoic acids and $\mathrm{N}$-tosylalkynylamides promoted by palladium indenediide pincer complexes. 
addition, analysis of the stereochemical outcome of the reaction (with internal alkynes or via D-labeling of terminal alkynes) indicated the exclusive formation of $Z$ products, in line with anti addition of the carboxylic acid/amide to the Pd-coordinated alkyne. But the exact ways the substrate is activated and the cyclization proceeds are still to be determined.

These two aspects (precise understanding of the mode of action of the Pd indenediide pincer complexes and further catalytic improvement) prompted us to perform detailed investigations combining theory and experiment. Here, we report DFT calculations and kinetic studies that shed light onto the mechanism of the cycloisomerization. The reaction is proposed to involve a second molecule of alkynoic acid acting as a proton shuttle, and this paved the way for catalytic enhancement. A broad variety of $\mathrm{H}$-bond donor additives have been screened and catechol derivatives were found to improve very significantly both activity and selectivity. The combination of Pd-ligand cooperative catalysis and proton shuttling was successfully applied to the cycloisomerization of internal 4- and 5-alkynoic acids.

\section{Results and discussion}

\section{DFT studies}

The mode of action of the Pd indenediide pincer complex in the cycloisomerization of alkynoic acids was first investigated computationally using DFT theory (B3PW91 functional). ${ }^{9}$ Calculations were performed on the real Pd system without simplification (phenyl groups were introduced at the $\mathrm{P}$ atoms, as in the first reported complexes ${ }^{7 a}$ ). A mononuclear T-shape SCS complex with a vacant coordination site was considered as starting species since the nature of the Pd pre-catalyst (co-ligand at Pd and mono vs. polynuclear character) was found to only marginally influence catalytic performance. ${ }^{7}$

The reaction profile for the cyclization of 4-pentynoic acid involving one molecule of substrate per Pd center was explored first (Fig. 1). The "active catalyst" Cat-1 is formed by side-on coordination of the alkyne to $\mathrm{Pd}$. The carboxylic acid is readily activated (with a barrier of only $12.2 \mathrm{kcal} \mathrm{mol}^{-1}$ ) and the proton is transferred to the indene backbone. Cyclization then occurs by nucleophilic attack of one oxygen atom to the alkyne affording Int-1B (the corresponding transition state $\mathbf{T S}_{\mathbf{1 B}}$ lies $24.2 \mathrm{kcal} \mathrm{mol}^{-1}$ above Cat-1). The catalytic cycle is closed by protonolysis of the vinyl-Pd species (back transfer of the proton from the indene backbone via $\mathbf{T S}_{\mathbf{1 C}}$ ) and substrate/product exchange at Pd. This reaction profile follows the mechanistic scenario commonly proposed to account for the metal-catalyzed cycloisomerization of alkynoic acids, ${ }^{\mathbf{1 0}}$ but two inconsistencies makes it very unlikely. First, the cyclization occurs by syn addition to the $\pi$-coordinated alkyne ( $\mathrm{O}$ attacks cis to $\mathrm{Pd}$ ) while anti addition is observed experimentally (as shown by D-labeling experiments). ${ }^{\mathbf{1 1}}$ Second, the activation barrier for the proton back-transfer leading to Int-1D $\left(54.4 \mathrm{kcal} \mathrm{mol}^{-1}\right.$ from Int-1B) is prohibitively high.

Given the results of the kinetic studies (vide infra), we envisioned to refine our model by involving a second molecule of alkynoic acid in the cycloisomerization process. Interaction of Cat-1 with 4-pentynoic acid is downhill in energy and leads to Cat-2 (Fig. 2). The alkyne bonded to Pd is oriented perpendicular to the coordination plane and its carboxylic acid moiety is engaged in $\mathrm{H}$-bonding. The second molecule of substrate approaches perpendicularly and its acidic proton lies in close proximity to the indene backbone. Accordingly, activation of the acid moiety is very easy (activation barrier of only 5.1 kcal mol${ }^{-1}$ ) and involves the "external" substrate as a proton shuttle between the $\pi$-bonded alkynoic acid and the electron-rich carbon atom C3 (transition state $\mathbf{T S}_{\mathbf{2 A}}$ ). The formation of Int-2A substantiates the non-innocent character of the indenediide backbone which is temporarily protonated. Cyclization then occurs by nucleophilic attack of one oxygen atom to the internal carbon atom of the alkyne $(\mathrm{Ci})$. The reaction is directed by an “external" substrate molecule which remains H-bonded during

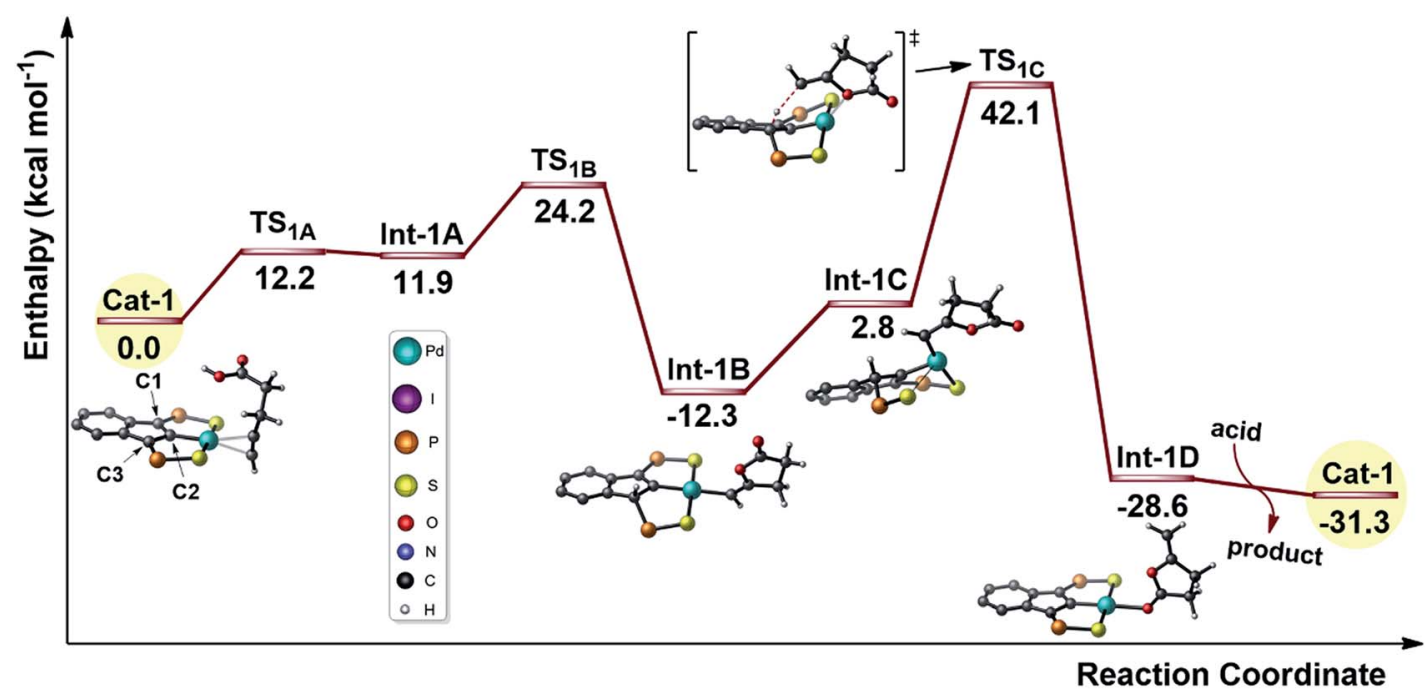

Fig. 1 Reaction profile $\left(\mathrm{kcal} \mathrm{mol}^{-1}\right)$ computed for the cyclization of 4-pentynoic acid involving one molecule of substrate per Pd center. The phenyl substituents on the $\mathrm{P}$ atoms are omitted for clarity. 
the whole process. It involves the rotation of the alkyne and its slippage (in $\mathbf{T S}_{\mathbf{2 B}}$, it is essentially $\sigma$-bonded via the terminal carbon atom $\mathrm{Ct}$ ). The cyclization requires important geometric changes, but it now proceeds via anti addition (in the resulting vinyl Pd complex Int-2B, the $\mathrm{O}$ atom is trans to $\mathrm{Pd}$ ) and the corresponding activation barrier is accessible $\left(27.8 \mathrm{kcal} \mathrm{mol}^{-1}\right.$ from Cat-2). The external substrate molecule weakly interacts with the proton at C3 in Int-2B, and subsequently relays the protonolysis of the vinyl Pd species. The formation of the alkylidene lactone is strongly exothermic (Int-2C lies 27.5 kcal mol ${ }^{-1}$ below Cat-2), and thanks to this proton shuttling, the associated activation barrier is readily accessible (only 13.5 $\mathrm{kcal} \mathrm{mol}^{-1}$ ). Product to substrate exchange at Pd closes the cycle and regenerates Cat-2.

Thus, involving two molecules of 4-pentynoic acid, it is possible to propose a catalytic cycle which is consistent with the experimental observations. The second molecule of substrate acts as a proton shuttle in the acid activation and in the protonolysis of the key vinyl Pd intermediate. It also directs the cyclization to anti addition.

\section{Kinetic studies}

In parallel with the DFT calculations, kinetic studies were performed. The partial orders in palladium and substrate were determined using the initial rate method. The iPr-substituted palladium dimer I (Fig. 3) was chosen as pre-catalyst (rather than the Ph-substituted iodo/chloropalladate complexes or the corresponding neutral trimer) because of practical reasons (better solubility and stability, absence of ammonium countercations). ${ }^{7 b}$ The cyclization of 5-hexynoic acid $\mathbf{1 a}$ was selected as model reaction and it proceeded within hours at $90{ }^{\circ} \mathrm{C}$ in
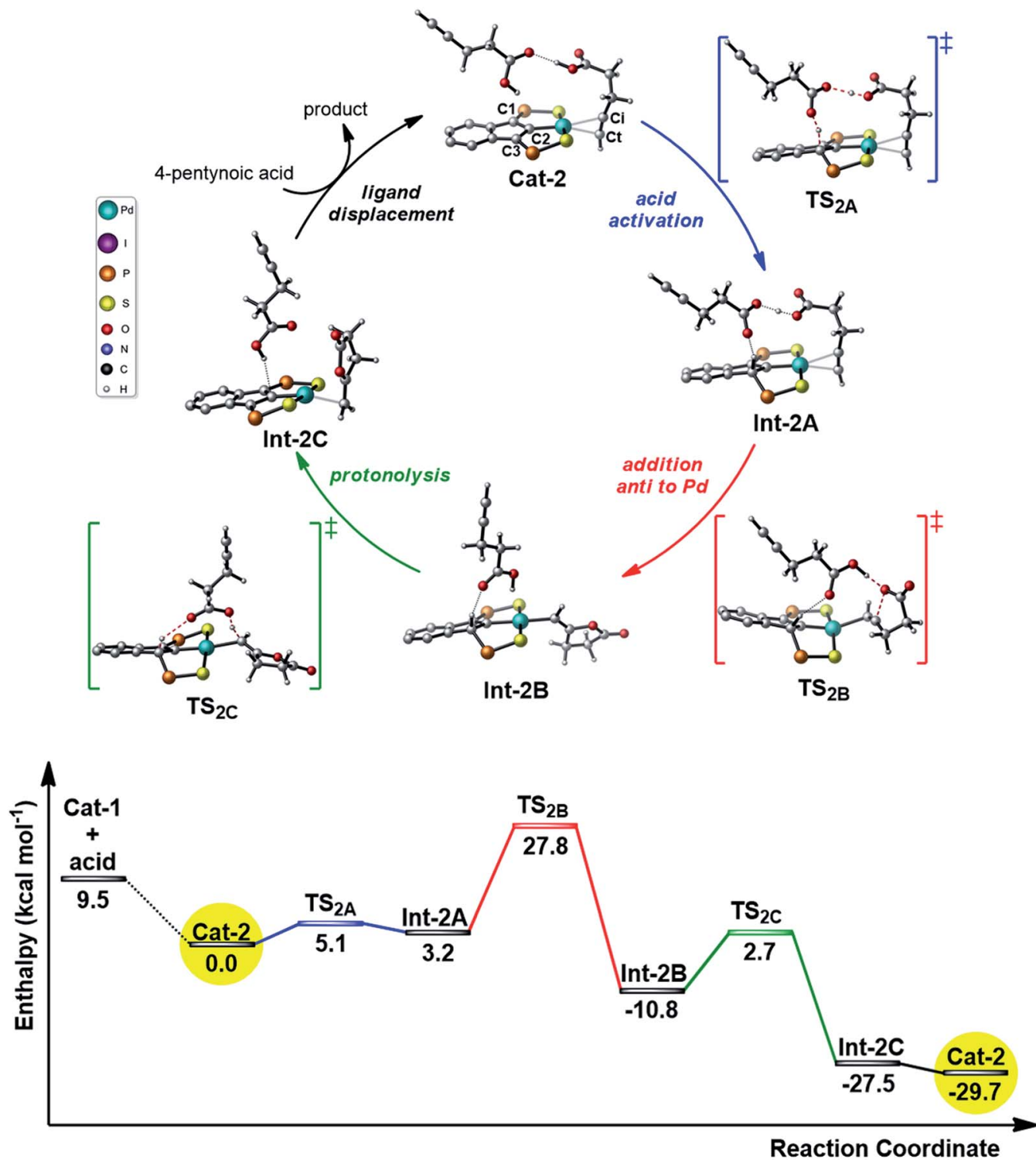

Fig. 2 Reaction profile ( $\mathrm{kcal} \mathrm{mol}^{-1}$ ) computed for the cyclization of 4-pentynoic acid involving two molecules of substrate per Pd center. The phenyl substituents on the $\mathrm{P}$ atoms are omitted for clarity, the key carbon atoms of the indene backbone are labelled C1/C2/C3 and the carbons atoms of the alkynyl substrate are labelled $\mathrm{Ct} / \mathrm{Ci}$. 


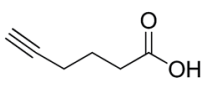

$1 a$
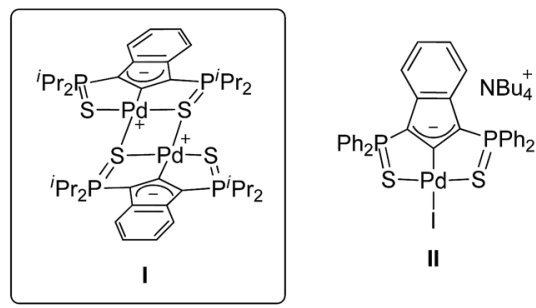

a)

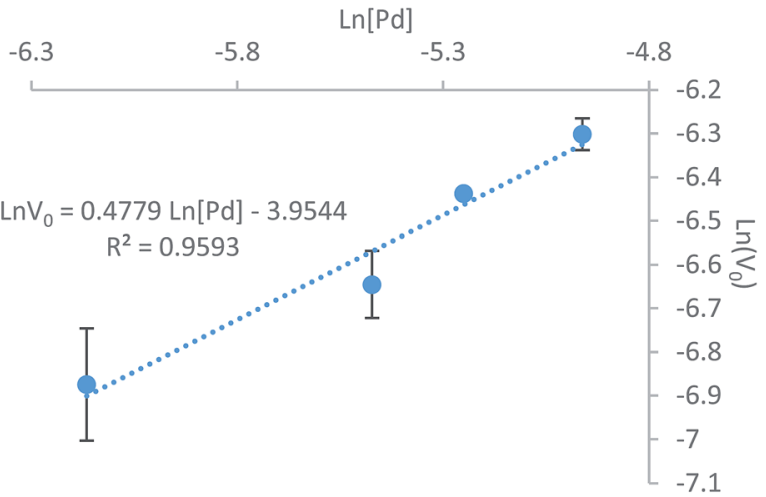

b)

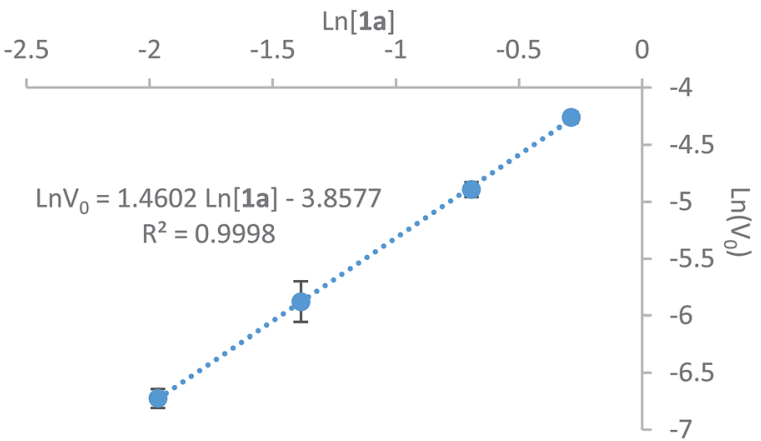

Fig. 3 Dependence of the initial rate of 5-hexynoic acid cyclization on the concentration of palladium (a) and substrate (b). The rates were averaged over three independent measurements. The error bars represent the standard deviation of the results from the three independent measurements.

deuterated chloroform and could thus be conveniently monitored by NMR using a pressure tube. Under these conditions, the Pd precatalyst and substrate are fully soluble and no induction period is observed. ${ }^{1} \mathrm{H}$ NMR monitoring shows the concomitant consumption of $\mathbf{1 a}$ and formation of methylenevalerolactone $\mathbf{2 a}$, and no intermediate or side-product is detected. The initial rates were determined at different Pd loadings $(3,5,7.5,10 \mathrm{~mol} \%$ in [Pd], Fig. S1 $\dagger)$ and at different substrate concentrations $(0.14-0.75 \mathrm{M}$, Fig. S4 $\dagger)$. The initial rates of the cycloisomerization reaction were determined by plotting the evolution of the methylene-valerolactone 2a concentration versus reaction time at the various concentrations of catalyst or substrate (Fig. S2 and S5 ${ }^{\dagger}$ ). Each experiment was run in triplicate for a better accuracy and the averaged values were linearly fitted to equations $\ln v_{0}=a \ln [\mathrm{Pd}]+b$ (Fig. 3a) and $\ln v_{0}=c \ln [\mathbf{1 a}]+d$ (Fig. 3b) for palladium and 5-hexynoic acid variations, respectively. Accordingly, the rate law can be expressed as follows: $v=k[\mathrm{Pd}]^{1 / 2}[\mathrm{Sub}]^{3 / 2}$.

The partial order of 0.5 in [Pd] clearly indicates that the dinuclear complex $\mathbf{I}$ is not the active species. It is in fact the resting state of the precatalyst, which dissociates and coordinates the substrate to give the active species. The dinuclear form is favored at room temperature (the SCS pincer ligand is dissymmetric and two distinct signals are observed by ${ }^{31} \mathrm{P}$ NMR), but tends to dissociate upon heating (the ${ }^{31} \mathrm{P} ~ \mathrm{NMR}$ signals progressively broaden and coalesce at $c a .90{ }^{\circ} \mathrm{C}$, Fig. S24†). Similar situations (square root order in [Pd] and offcycle equilibrium of the active mononuclear species with an inactive dimeric form) have been encountered in Pd-catalyzed Heck couplings and $\mathrm{C}-\mathrm{H}$ acetoxylation of benzene. ${ }^{\mathbf{1 2}}$

The partial order of 1.5 in [1a] also deserves comment. It is unexpected and reveals that the reaction is not a simple unimolecular process, as may be anticipated for a cycloisomerization. The way the substrate reacts is apparently more complicated and in line with the reaction profile computed by DFT, and it is proposed that a second molecule of alkynoic acid is involved in the catalytic cycle. The partial order in [1a] determined experimentally at $90{ }^{\circ} \mathrm{C}$ is not 2 but 1.5 , probably due to the tendency of carboxylic acids to form dimers in solution. ${ }^{13}$ This self-association phenomenon tends to reduce the partial order in substrate. It has been tracked by IR and a dimer to monomer ratio of 7.5 has been determined for $\mathbf{1 a}$ at $25{ }^{\circ} \mathrm{C}$ and $0.14 \mathrm{~mol} \mathrm{~L}^{-1} \cdot{ }^{14}$

According to calculations, the second molecule of substrate participates via $\mathrm{H}$-bonding and acts as a proton shuttle. We were thus intrigued about the possibility to use $\mathrm{H}$-bond donors as additives in these cycloisomerization processes. These additive could substitute the "external" molecule of substrate, and optimizing the structure of the additive may afford the opportunity to enhance the catalytic performance of the Pd complex in terms of both activity and selectivity.

\section{Screening of $\mathbf{H}$-bond donor additives}

The influence of additives was first investigated on 4-pentynoic acid $\mathbf{1 b}$, since its cyclization is easier to perform (it proceeds

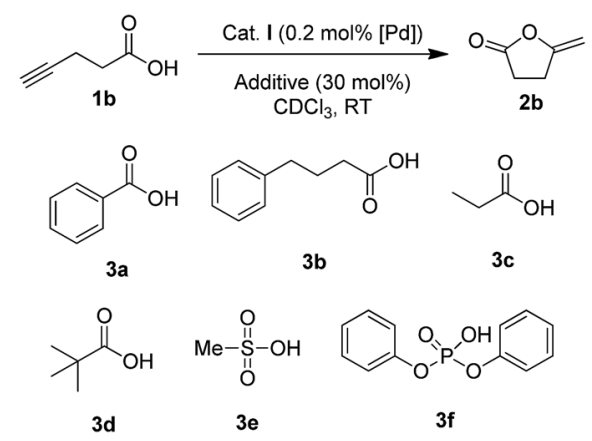

Scheme 1 Additives having no impact $(3 a-d)$ or inhibiting $(3 e, f)$ the cyclization of 4 -pentynoic acid $1 \mathrm{~b}$. 
within hours at rt with complex I). We started the screening with aliphatic and aromatic carboxylic acids 3a-d (30 mol\%) (Scheme 1), but in all cases, the conversion of $\mathbf{1 b}$ was essentially unaffected $(\sim 75 \%$ after $1 \mathrm{~h}, \sim 86 \%$ after $2 \mathrm{~h}$, Table $\mathrm{S} 9 \dagger) .{ }^{15}$ Stronger acids such as methane sulfonic acid $3 \mathbf{e}$ and diphenylphosphoric acid $3 \mathbf{f}$ completely inhibited the reaction, probably due to the protonation of the indenediide backbone, giving inactive indenyl species.

Then, we turned our attention to alcohols, starting with catechol (4a) which has already been used as additive in organocatalyzed aldol reactions. ${ }^{16}$ The addition of $30 \mathrm{~mol} \%$ of $\mathbf{4 a}$ significantly speeds up the cycloisomerization of $\mathbf{1 b}$ (complete conversion required only $30 \mathrm{~min}$ instead of $5 \mathrm{~h}$ without additive). To confirm the impact of $\mathbf{4 a}$, it was then tested on the cyclization of 5-hexynoic acid 1a (which is much less reactive than $\mathbf{1 b}$ ), and again the reaction time was significantly reduced (from $10 \mathrm{~h}$ to $30 \mathrm{~min}$ to achieve complete conversion at $90^{\circ} \mathrm{C}$ ). These encouraging results prompted us to screen a broad variety of alcohols, diols and triols with aliphatic and aromatic skeletons. Overall, 24 compounds (4a-x) were tested on the cyclization of 5-hexynoic acid 1a. Selected results are displayed in Fig. 4 (see Fig. S26 and S27† for more details).

Simple alcohols have little or no impact, but diols and triols were found to significantly improve the conversion, in particular the aromatic ones. ${ }^{17}$ After 30 min, the conversion of $\mathbf{1 a}$ is only of $27 \%$ when the Pd complex I is used alone, but it is complete when 8 additives are adjoined: catechol $\mathbf{4 a}$, its derivatives substituted with electron-withdrawing groups (4u, $4 \mathbf{4 v}, \mathbf{4 w}$ and $\mathbf{4 x}$ ), 1,2,3-benzenetriol $\mathbf{4 p}, 1,8$-dihydroxynaphtalene $\mathbf{4 m}$ and 2,3-dihydroxynaphthalene $\mathbf{4 n}$. The most efficient additives are those featuring proximal hydroxyl groups, to ensure optimal proton transfer. This is particularly apparent when comparing hydroquinone 40 (which has only little effect) and catechol. ${ }^{18}$ The proton transfer may involve the two hydroxyl groups (proton shuttling via H-bonding, Scheme 2a) or only one (Scheme 2b, the other hydroxyl group can participate in adjacent H-bonding).

In order to discriminate the additives enabling complete conversion of 1a after $30 \mathrm{~min}$, their loading was reduced, first to $10 \mathrm{~mol} \%$ (Fig. 4b) and then to $5 \mathrm{~mol} \%$ (Table S10†). Under these conditions, conversions of $90 \%$ or more were also achieved. The best results were obtained with 4-nitrocatechol $\mathbf{4 x}$ which gave full conversion of $1 \mathrm{a}$ within $30 \mathrm{~min}$, even at $5 \mathrm{~mol} \%$. With this leading additive, we sought to optimize the reaction conditions (Table 1). Using $5 \mathrm{~mol} \%$ of Pd and $5 \mathrm{~mol} \%$ of $4 \mathbf{x}$, the reaction temperature could be significantly decreased (entries 2 and 3): at $60{ }^{\circ} \mathrm{C}$, 5-hexynoic acid $1 \mathrm{a}$ was fully consumed in $30 \mathrm{~min}$, and even at $40^{\circ} \mathrm{C}$, full conversion was reached in only $1 \mathrm{~h}$, while $10 \mathrm{~h}$ of reaction at $90{ }^{\circ} \mathrm{C}$ are needed without additive. The catalyst loading could also be significantly reduced. Using $5 \mathrm{~mol} \%$ of 4 nitrocatechol $\mathbf{4 x}$ and only $1 \mathrm{~mol} \%$ of Pd, 1a was completely cycloisomerized within $30 \mathrm{~min}$ at $90{ }^{\circ} \mathrm{C}$ (entry 4). Full conversion could also be achieved with only $0.2 \mathrm{~mol} \%$ of Pd and 1 mol\% of 4-nitrocatechol $\mathbf{4 x}$ after $36 \mathrm{~h}$ at $90{ }^{\circ} \mathrm{C}$ (entry 5).

The impact of the additive on the kinetics of the reaction, and in particular on the partial order in substrate, was then explored. Tetrachlorocatechol $\mathbf{4} \mathbf{u}$ was chosen as the additive for
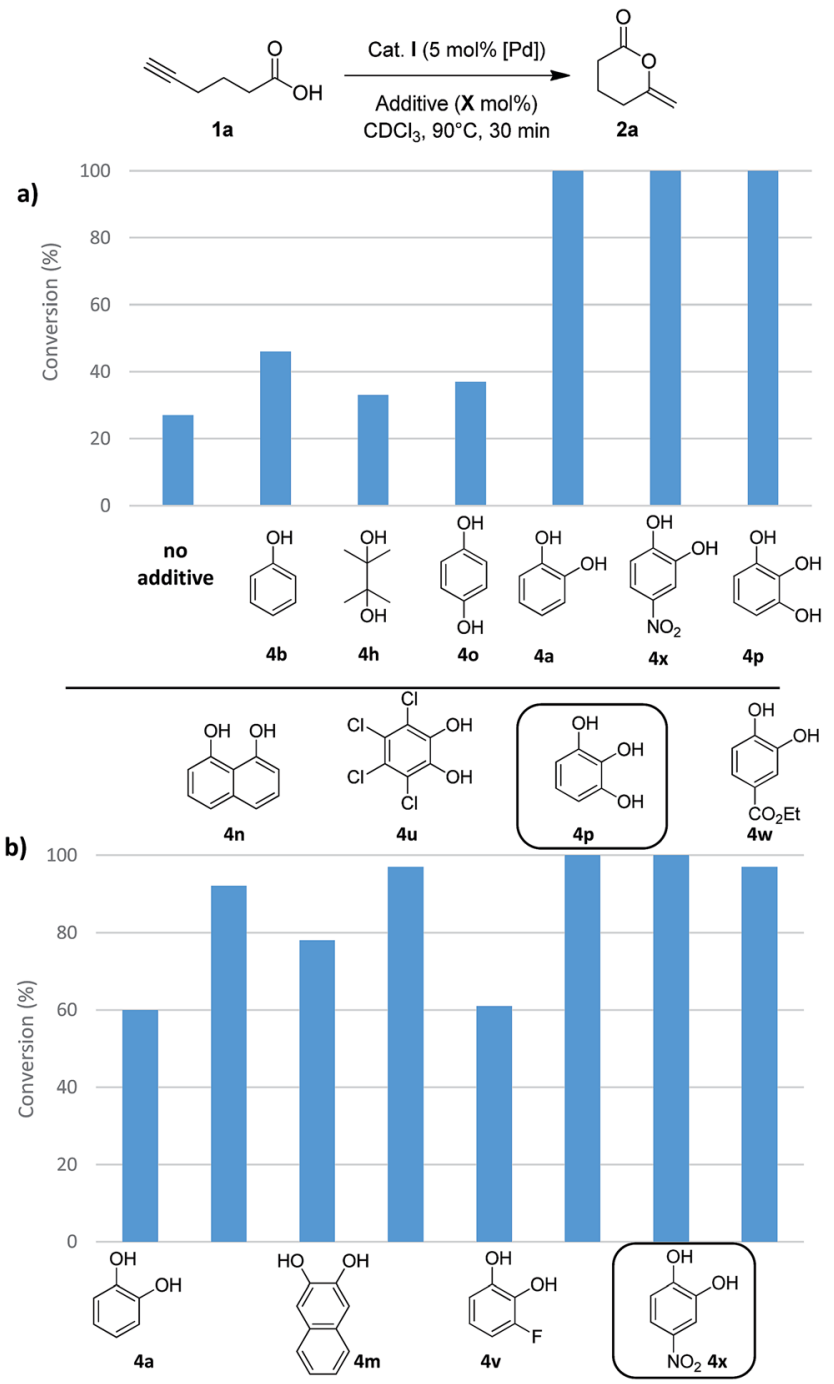

Fig. 4 Impact of $\mathrm{H}$-donor additives on the cyclization of 5-hexynoic acid $1 \mathrm{a}$. The reaction is performed with 30 or $10 \mathrm{~mol} \%$ of additives (a and $b$, respectively) and the conversion of $1 \mathrm{a}$ after $30 \mathrm{~min}$ is reported.

solubility issues, and its loading was varied (catechol to $\mathrm{Pd}$ ratio of $0.2,1,2$ and 4 ). The reactions were carried out at $25{ }^{\circ} \mathrm{C}$ to ensure accurate NMR monitoring. ${ }^{9}$ A strong impact of the catechol was observed, with a significant decrease of the partial order in substrate (from 1.33 without additive, to 0.62 for a catechol to $\mathrm{Pd}$ ratio of 0.2 , and even to 0.26 for a catechol to $\mathrm{Pd}$ ratio of 4). Self-association of the carboxylic acid as well as crossed association with the catechol probably comes into play

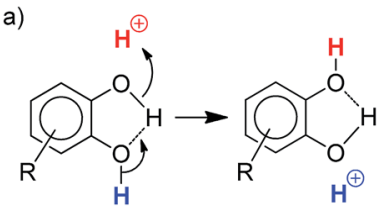

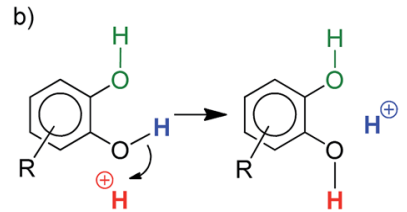

Scheme 2 Schematic representation of two different modes of proton transfer with catechol derivatives. 
Table 1 Optimization of the reaction conditions for the cyclization of 5-hexynoic acid 1a catalyzed by complex I, with 4-nitrocatechol $4 \mathrm{x}$ as additive

\begin{tabular}{llllll}
\hline Entry $^{a}$ & $\begin{array}{l}\text { Mol\% } \\
\mathrm{Pd}\end{array}$ & Mol\% additive & $\begin{array}{l}\mathrm{T} \\
\left({ }^{\circ} \mathrm{C}\right)\end{array}$ & Time & Conversion $^{b}$ \\
\hline 1 & 5 & 5 & 90 & $30 \mathrm{~min}$ & $>99 \%$ \\
2 & 5 & 5 & 60 & $30 \mathrm{~min}$ & $>99 \%$ \\
3 & 5 & 5 & 40 & $1 \mathrm{~h}$ & $>99 \%$ \\
4 & 1 & 5 & 90 & $40 \mathrm{~min}$ & $>99 \%$ \\
5 & 0.2 & 1 & 90 & $36 \mathrm{~h}$ & $>99 \%$
\end{tabular}

${ }^{a}$ Catalytic reactions performed under argon using $0.1 \mathrm{mmol}$ of $1 \mathrm{a}(0.14$ $\mathrm{M}$ in $\left.\mathrm{CDCl}_{3}\right)$ and dimer $\mathbf{I}(5 \mathrm{~mol} \%[\mathrm{Pd}]){ }^{b}$ Conversion were determined by ${ }^{1} \mathrm{H}$ NMR analysis.

here and it is not surprising that fractional orders below 1 are obtained.

In order to gain insight into the effect of the additive, the reaction profile for the cyclization of 4-pentynoic acid in the presence of catechol (chosen for symmetry reasons) was computed at the DFT level (Fig. 5).

As for the mechanism involving two carboxylic acid molecules, the first step corresponds to the activation of the carboxylic acid with protonation of the indenyl backbone (transition state $\mathbf{T S}_{\mathbf{3 A}}$ ). In this case, it is assisted by the catechol molecule. One hydroxyl group acts as a relay for the proton transfer (from the substrate to the indenyl) while the second hydroxyl is involved in hydrogen bonding with the $\mathrm{C}=\mathrm{O}$ group of the carboxylic acid ( $c f$. Scheme 2b). Then, the cyclization occurs via anti-attack of the carboxylate, which is engaged in double hydrogen bonding with the catechol $\left(\mathbf{T S}_{3 \mathrm{C}}\right)$. Finally, the proton borrowed by the indenyl backbone is transferred back and the alkylidene lactone is released. In this case, this is a twostep process, with protonation of the vinyl Pd species by catechol and then proton transfer from the indenyl to the catechol (see ESI $\dagger$ ). The catechol acts here a proton shuttle (see Scheme 2a), in a similar way to the "external" molecule of carboxylic acid. Note that the rate-determining step is again the cyclization and that the corresponding activation barrier is about $3 \mathrm{kcal}$ $\mathrm{mol}^{-1}$ lower in energy than that computed for the mechanism involving two carboxylic acid molecules, in line with the rate improvement observed experimentally.

\section{Cycloisomerization of internal alkynoic acids in the presence of catechol additives}

The cyclization of alkynoic acids bearing internal alkynes is notoriously challenging. These substrates are much less reactive than terminal alkynoic acids, and exo/endo selectivity issues are frequently met. ${ }^{11,19,20}$ We were thus very eager to assess the influence of catechol additives in such difficult cycloisomerizations. Catalytic runs were performed at $90{ }^{\circ} \mathrm{C}$ with $5 \mathrm{~mol} \%$ of Pd (dimer I) and $30 \mathrm{~mol} \%$ of additive (either 4nitrocatechol $4 \mathbf{x}$ or 1,2,3-benzenetriol $4 \mathbf{p}$ ) on four representative substrates (Table 2).

Pd complexes have rarely been used to catalyze the cycloisomerization of internal 4-alkynoic acids. ${ }^{19 a, b}$ Compounds 1c and $1 \mathbf{d}$ were tested and in both cases, the additives spectacularly shortened the reaction time (entries 1 and 2). The cyclization of 1c could be completed within $10 \mathrm{~min}$ (instead of $1.5 \mathrm{~h}$ ) and that of 1d required only $30 \mathrm{~min}$ (instead of $28 \mathrm{~h}$ ), representing speeds up by approximately 10 to 60 times. The additives also noticeably influenced the regioselectivity of the cyclization and favored the formation of 6-membered lactones (6-endo $v s$. 5-exo cyclization). Starting from 1c, a $1 / 1.2$ mixture of $2 \mathbf{c}_{\text {exo }} / 2 \mathbf{c}_{\text {endo }}$ products was obtained with Pd dimer I alone, while in the presence of the additives, $\mathbf{2} \mathbf{c}_{\text {endo }}$ largely prevailed (the selectivity reached 1/7.3 with $\mathbf{4 p}$ ). In the case of 4-hexynoic acid 1d, the catechol additives even switched the selectivity and the 6-endo cyclized product $\mathbf{2} \mathbf{d}_{\text {endo }}$ could be obtained with a selectivity of up to $1 / 2.3$ in the case of 1,2,3-benzenetriol $\mathbf{4 p .}$

We then investigated the cycloisomerization of internal 5-alkynoic acids which has been scarcely achieved, using gold complexes. ${ }^{20}$ The Pd dimer I was previously shown to efficiently

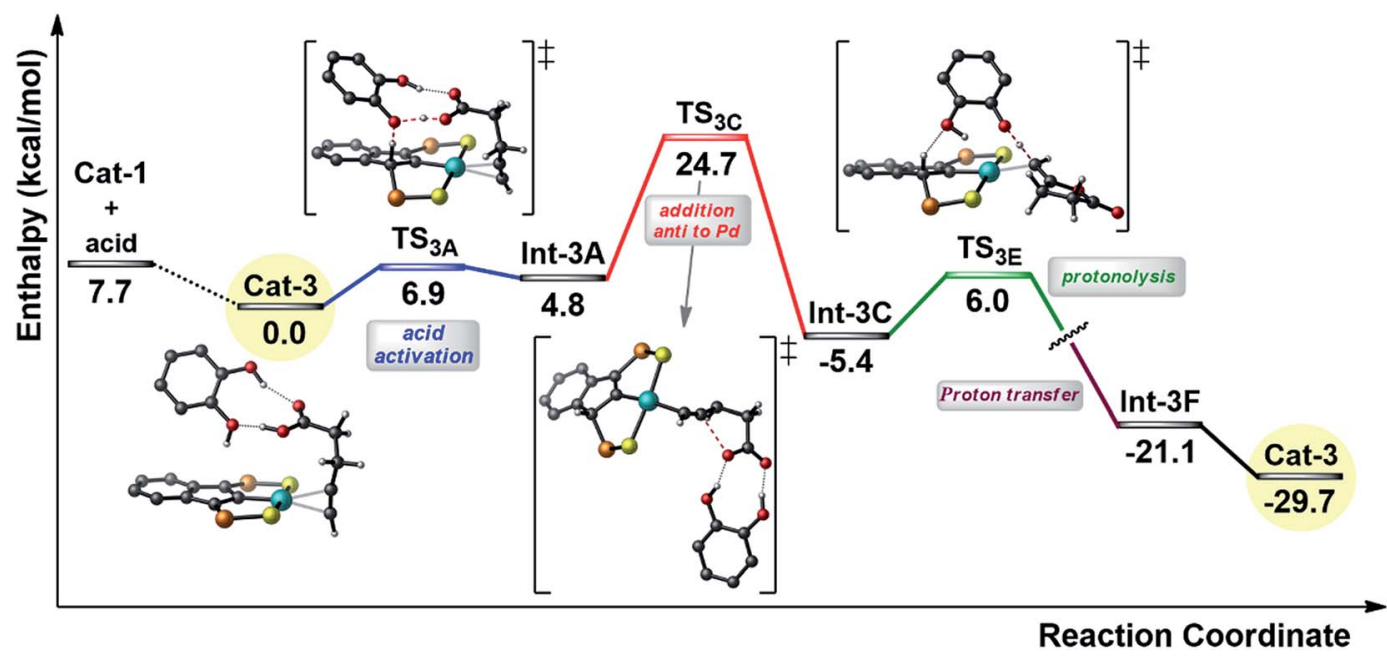

Fig. 5 Simplified reaction profile ( $\mathrm{kcal} \mathrm{mol}^{-1}$ ) computed for the cyclization of 4-pentynoic acid in the presence of catechol. The phenyl substituents on the $\mathrm{P}$ atoms are omitted for clarity. 
Table 2 Influence of catechol additives on the cycloisomerization of alkynoic acids bearing internal alkynes

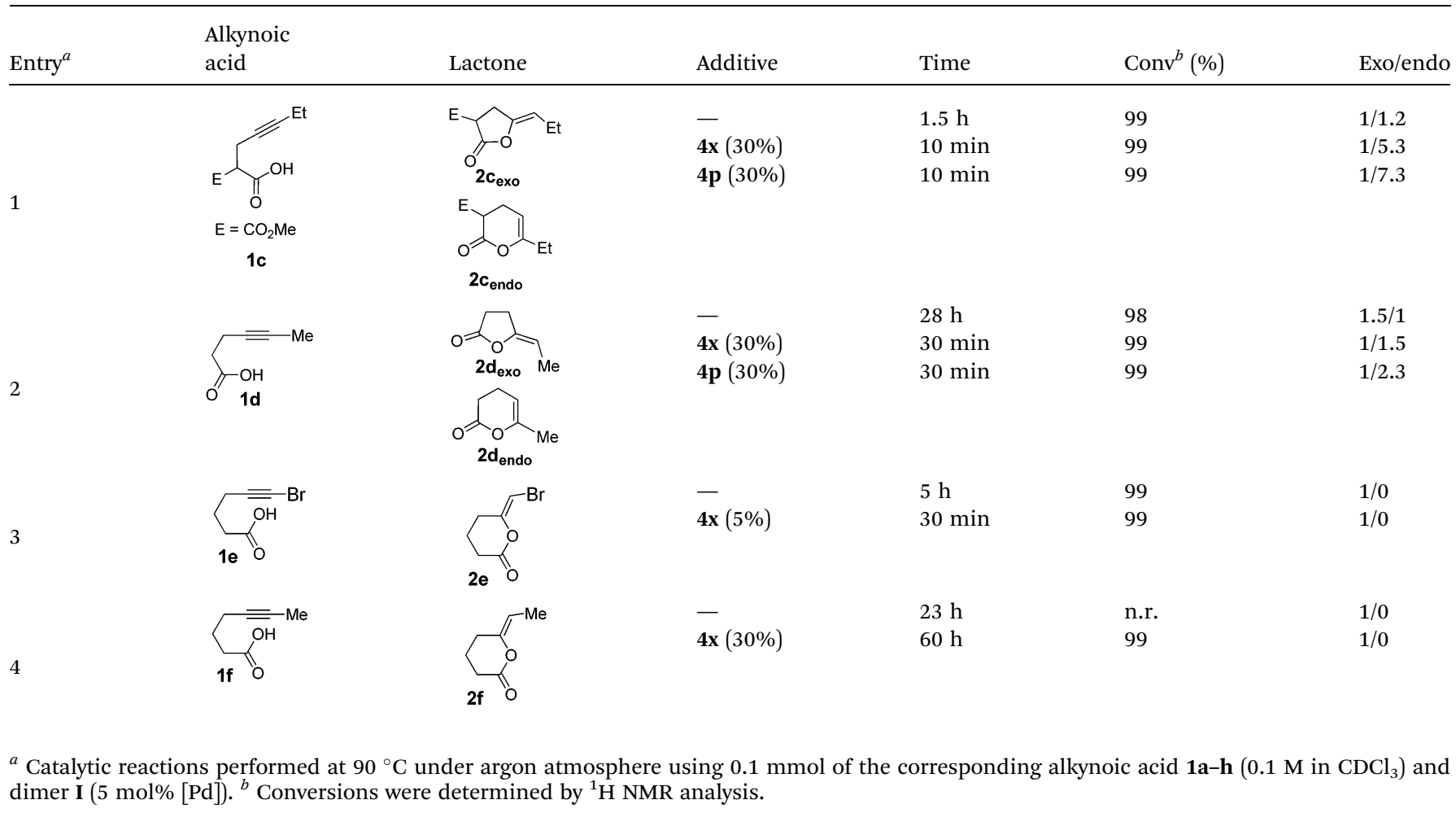

cycloisomerize 6-bromo-5-hexynoic acid 1e, a relatively activated substrate, and the corresponding 6-membered alkylidenelactone $2 \mathrm{e}$ could be quantitatively obtained within $5 \mathrm{~h}$ (entry 3 ). In the presence of 4-nitrocatechol $\mathbf{4 x}$, the reaction time was again drastically decreased. Full conversion was achieved in only $20 \mathrm{~min}$ using $5 \mathrm{~mol} \%$ of the additive. Note that $2 \mathrm{e}$ is obtained exclusively in its $Z$ form as the result of anti addition of the carboxylate to the Pd-coordinated alkyne. The catechol additive has an even more striking influence on the cyclization of 5-heptynoic acid $\mathbf{1 f}$ (entry 4). No reaction occurred with Pd dimer I alone, even after prolonged heating, but in the presence of 4-nitrocatechol (30 mol\%), complete conversion was achieved within $60 \mathrm{~h}$. Under these conditions, simple hydration of the alkyne tends to compete with the cyclosiomerization, ${ }^{9}$ but the targeted 6-membered alkylidene-lactone $2 \mathbf{f}$ was obtained in good yield (70\%), again as a unique isomer $(Z)$.

\section{Conclusions}

The precise mode of action of SCS indenediide Pd complexes in the cycloisomerization of alkynoic acids has been determined thanks to DFT and kinetic studies. Cooperation between the Pd center and the backbone of the pincer ligand has been confirmed computationally. In addition, the mechanistic study revealed the involvement of a second molecule of alkynoic acid all along the catalytic cycle: it acts as a proton shuttle in the activation of the acid and in the protonolysis of the intermediate vinyl Pd species, it also directs the nucleophilic attack of the carboxylic acid on the $\pi$-coordinated alkyne (anti addition). The possibility of replacing the second substrate molecule by an additive was investigated. A variety of $\mathrm{H}$-bond donors were screened and polyols featuring proximal hydroxyl groups led to significant catalytic enhancement. Catechol derivatives substituted by electron-withdrawing groups proved highly beneficial on both activity and selectivity. The impact of 4-nitrocatechol $\mathbf{4 x}$ and 1,2,3-benzenetriol $\mathbf{4 p}$ on the cyclization of internal alkynoic acids is spectacular (endo/exo selectivities up to $7.3 / 1$ and 60 -fold increase in reactivity were achieved).

This work also illustrates the interest to perform mechanistic studies on catalytic transformations. It enables us to understand the key factors influencing their efficiency and/or selectivity, and paves the way for further improvement. In this study, the combination of metal-ligand cooperation and proton shuttling by a second molecule of substrate has been pointed out. The ability of protic substrates, solvents or water molecules to act as proton shuttles in transition-metal catalyzed transformations has been occasionally proposed and supported by DFT calculations. ${ }^{21}$ We have shown here that this role can be transferred to an $\mathrm{H}$-bond donor additive, and that optimizing the structure of this additive can significantly enhance the catalytic activity and selectivity. Proton shuttling is relatively well-established in organic synthesis and polymerization catalysis. ${ }^{22}$ We believe it is also highly relevant in transition-metal catalysis ${ }^{23}$ and can be applied to a variety of transformations.

\section{Acknowledgements}

Financial support from the Centre National de la Recherche Scientifique, the Université de Toulouse, and the Agence 
Nationale de la Recherche (ANR CE6-CYCLOOP) is acknowledged. The authors are grateful to CalMip (CNRS, Toulouse, France) for calculation facilities. L. M. thanks the Institut Universitaire de France.

\section{Notes and references}

1 (a) D. Lupp, N. J. Christensen and P. Fristrup, Dalton Trans., 2014, 43, 11093; (b) A. J. Nett, W. Zhao, P. M. Zimmerman and J. Montgomery, J. Am. Chem. Soc., 2015, 137, 7636.

2 For selected references, see: (a) N. R. Deprez and M. S. Sanford, J. Am. Chem. Soc., 2009, 131, 11234; (b) S. Ge, R. A. Green and J. F. Hartwig, J. Am. Chem. Soc., 2014, 136, 1617; (c) J. S. Bair, Y. Schramm, A. G. Sergeev, E. Clot, O. Eisenstein and J. F. Hartwig, J. Am. Chem. Soc., 2014, 136, 13098; (d) P. M. Pérez Garcia, P. Ren, R. Scopelliti and X. Hu, ACS Catal., 2015, 5, 1164.

3 G. C. Lloyd-Jones and M. P. Muñoz, J. Labelled Compd. Radiopharm., 2007, 50, 1072.

4 For selected references, see : (a) O. R. Luca, J. D. Blakemore, S. J. Konezny, J. M. Praetorius, T. J. Schmeier, G. B. Hunsinger, V. S. Batista, G. W. Brudvig, N. Hazari and R. H. Crabtree, Inorg. Chem., 2012, 51, 8704; (b) T. Stahl, P. Hrobarik, C. D. Konigs, Y. Ohki, K. Tatsumi, S. Kemper, M. Kaupp, H. F. T. Klare and M. Oestreich, Chem. Sci., 2015, 6, 4324.

5 For selected references, see: (a) A. C. Tsipis, Coord. Chem. Rev., 2014, 272, 1; (b) H. Li and M. B. Hall, ACS Catal., 2015, 5, 1895; (c) G. J. Cheng, X. Zhang, L. W. Chung, L. Xu and Y. D. Wu, J. Am. Chem. Soc., 2015, 137, 1706; (d) G. Jindal, H. K. Kisan and R. B. Sunoj, ACS Catal., 2014, 5, 480.

6 (a) P. Oulié, N. Nebra, N. Saffon, L. Maron, B. Martin-Vaca and D. Bourissou, J. Am. Chem. Soc., 2009, 131, 3493; (b) N. Nebra, J. Lisena, N. Saffon, L. Maron, B. Martin-Vaca and D. Bourissou, Dalton Trans., 2011, 40, 8912; (c) P. Oulié, N. Nebra, S. Ladeira, B. Martin-Vaca and D. Bourissou, Organometallics, 2011, 30, 6416; (d) N. Nebra, N. Saffon, L. Maron, B. Martin-Vaca and D. Bourissou, Inorg. Chem., 2011, 50, 6378; (e) N. Nebra, S. Ladeira, L. Maron, B. Martin-Vaca and D. Bourissou, Chem.-Eur. J., 2012, 18, 8474; (f) J. Lisena, J. Monot, S. Mallet-Ladeira, B. Martin-Vaca and D. Bourissou, Organometallics, 2013, 32, 4301.

7 (a) N. Nebra, J. Monot, R. Shaw, B. Martin-Vaca and D. Bourissou, ACS Catal., 2013, 3, 2930; (b) N. A. EspinosaJalapa, D. Ke, N. Nebra, L. Le Goanvic, S. Mallet-Ladeira, J. Monot, B. Martin-Vaca and D. Bourissou, ACS Catal., 2014, 4, 3605.

8 A. Scharf, I. Goldberg and A. Vigalok, J. Am. Chem. Soc., 2013, 135, 967.

9 See ESI† for details.

10 (a) D. M. T. Chan, T. B. Marder, D. Milstein and N. J. Taylor, J. Am. Chem. Soc., 1987, 109, 6385; (b) T. B. Marder, D. M. T. Chan, W. C. Fultz, J. C. Calabrese and D. Milstein, Chem. Commun., 1987, 1885.
11 Cycloisomerization with syn-addition has been occasionally observed, see: S. Elgafi, D. Leslie, A. Barbara and A. Messerle, J. Organomet. Chem., 2000, 607, 97.

12 (a) G. P. F. v. Strijdonck, M. D. K. Boele, P. C. J. Kamer, J. G. de Vries and P. W. N. M. van Leeuwen, Eur. J. Inorg. Chem., 1999, 1999, 1073; (b) T. Rosner, J. Le Bars, A. Pfaltz and D. G. Blackmond, J. Am. Chem. Soc., 2001, 123, 1848; (c) A. Sud, R. M. Deshpande and R. V. Chaudhari, J. Mol. Catal. A: Chem., 2007, 270, 144; (d) A. K. Cook and M. S. Sanford, J. Am. Chem. Soc., 2015, 137, 3109.

13 For a representative example see: F. Ragaini, M. Gasperini, S. Cenini, L. Arnera, A. Caselli, P. Macchi and N. Casati, Chem.-Eur. J., 2009, 15, 8064.

14 For sake of consistency, the partial order in 1a was also measured at $25{ }^{\circ} \mathrm{C}$. It is even lower than at $90{ }^{\circ} \mathrm{C}(1.33 \mathrm{vs}$. 1.46), in line with an increase of the dimer to monomer ratio for entropic reasons.

15 The progress of the reaction was followed by ${ }^{1} \mathrm{H}$ NMR spectroscopy by integrating the resonance signal of the vinylic proton of the lactone $2 \mathbf{b}(\delta=4.30 \mathrm{ppm})$ and the acetylenic proton of the starting material $(\delta=1.99 \mathrm{ppm})$.

16 For catechol as additive, see: (a) C. Ji, Y. Peng, C. Huang, N. Wang, Z. Luo and Y. Jiang, J. Mol. Catal. A: Chem., 2006, 246, 136; (b) D. A. DiRocco and T. Rovis, J. Am. Chem. Soc., 2011, 133, 10402; (c) J. Luo, R. Tan, Y. Kong, C. Li and D. Yin, Chin. J. Catal., 2012, 33, 1133. For catechol derivatives as additives, see: $(d)$ T. J. Peelen, Y. Chi and S. H. Gellman, J. Am. Chem. Soc., 2005, 127, 11598; (e) M. J. Campbell and J. S. Johnson, J. Am. Chem. Soc., 2009, 131, 10370; (f) C. M. Filloux, S. P. Lathrop and T. Rovis, Proc. Natl. Acad. Sci. Unit. States Am., 2010, 107, 20666; (g) X. Chen, X. Fang and Y. R. Chi, Chem. Sci., 2013, 4, 2613.

17 Control experiments with catechol $4 \mathbf{a}$ and 4-nitrocatechol $\mathbf{4 x}$ showed that no reaction occurs in the absence of palladium complex I.

18 Similarly, 1,2,3,-benzenetriol $4 p$ gave better results than 1,2,4- and 1,3,5-benzenetriols $\mathbf{4 q}$ and $\mathbf{4 r}$.

19 For Pd-catalyzed cycloisomerization of internal 4-alkynoic acids, see: (a) J. Garcia-Alvarez, J. Diez and C. Vidal, Green Chem., 2012, 14, 3190; (b) V. Sridharan, L. Fan, S. Takizawa, T. Suzuki and H. Sasai, Org. Biomol. Chem., 2013, 11, 5936; For cycloisomerization of internal 4alkynoic acids catalyzed by other transition metals, see: $(c)$ P. Pale and J. Chuche, Tetrahedron Lett., 1987, 28, 6447; (d) T. Wakabayashi, Y. Ishii, K. Ishikawa and M. Hidai, Angew. Chem., Int. Ed. Engl., 1996, 35, 2123; (e) I. Takei, Y. Wakebe, K. Suzuki, Y. Enta, T. Suzuki, Y. Mizobe and M. Hidai, Organometallics, 2003, 22, 4639; (f) E. Genin, P. Y. Toullec, S. Antoniotti, C. Brancour, J. P. Genêt and V. Michelet, J. Am. Chem. Soc., 2006, 128, 3112; $(g)$ J. Aleman, V. del Solar and C. Navarro-Ranninger, Chem. Commun., 2010, 46, 454; (h) E. Tomas-Mendivil, P. Y. Toullec, J. Diez, S. Conejero, V. Michelet and V. Cadierno, Org. Lett., 2012, 14, 2520; (i) E. TomasMendivil, P. Y. Toullec, J. Borge, S. Conejero, V. Michelet and V. Cadierno, ACS Catal., 2013, 3, 3086; (j) L. C. Lee and Y. Zhao, J. Am. Chem. Soc., 2014, 136, 5579; (k) 
M. J. Rodriguez-Alvarez, C. Vidal, J. Diez and J. GarciaAlvarez, Chem. Commun., 2014, 50, 12927; (l) X. Z. Shu, S. C. Nguyen, Y. He, F. Oba, Q. Zhang, C. Canlas, G. A. Somorjai, A. P. Alivisatos and F. D. Toste, J. Am. Chem. Soc., 2015, 137, 7083.

20 For cycloisomerization of internal 5-alkynoic acids, see: $(a)$ H. Harkat, J. M. Weibel and P. Pale, Tetrahedron Lett., 2006, 47, 6273; (b) H. Harkat, A. Y. Dembelé, J. M. Weibel, A. Blanc and P. Pale, Tetrahedron, 2009, 65, 1871.

21 (a) F. Q. Shi, X. Li, Y. Xia, L. Zhang and Z. X. Yu, J. Am. Chem. Soc., 2007, 129, 15503; (b) L. Bellarosa, J. Díez, J. Gimeno, A. Lledos, F. J. Suárez, G. Ujaque and C. Vicent, Chem.-Eur. J., 2012, 18, 7749; (c) U. Gellrich, J. R. Khusnutdinova, G. M. Leitus and D. Milstein, J. Am. Chem. Soc., 2015, 137, 4851; (d) R. Yuan and Z. Lin, ACS Catal., 2015, 5, 2866; (e) S. Qu, Y. Dang, C. Song, M. Wen, K. W. Huang and Z. X. Wang, J. Am. Chem. Soc., 2014, 136, 4974.
22 For an example in organic catalysis, see: (a) M. Dryzhakov, M. Hellal, E. Wolf, F. C. Falk and J. Moran, J. Am. Chem. Soc., 2015, 137, 9555; For examples in polymerization, see: (b) M. Terada, Chem. Commun., 2008, 4097; (c) N. Susperregui, D. Delcroix, B. Martin-Vaca, D. Bourissou and L. Maron, J. Org. Chem., 2010, 75, 6581; (d) D. Delcroix, A. Couffin, N. Susperregui, C. Navarro, L. Maron, B. Martin-Vaca and D. Bourissou, Polym. Chem., 2011, 2, 2249.

23 (a) S. Zhou, S. Fleischer, K. Junge and M. Beller, Angew. Chem., Int. Ed., 2011, 50, 5120; (b) W. Tang, S. Johnston, J. A. Iggo, N. G. Berry, M. Phelan, L. Lian, J. Bacsa and J. Xiao, Angew. Chem., Int.Ed., 2013, 52, 1668; (c) B. R. Goldsmith, T. Hwang, S. Seritan, B. Peters and S. L. Scott, J. Am. Chem. Soc., 2015, 137, 9604. 